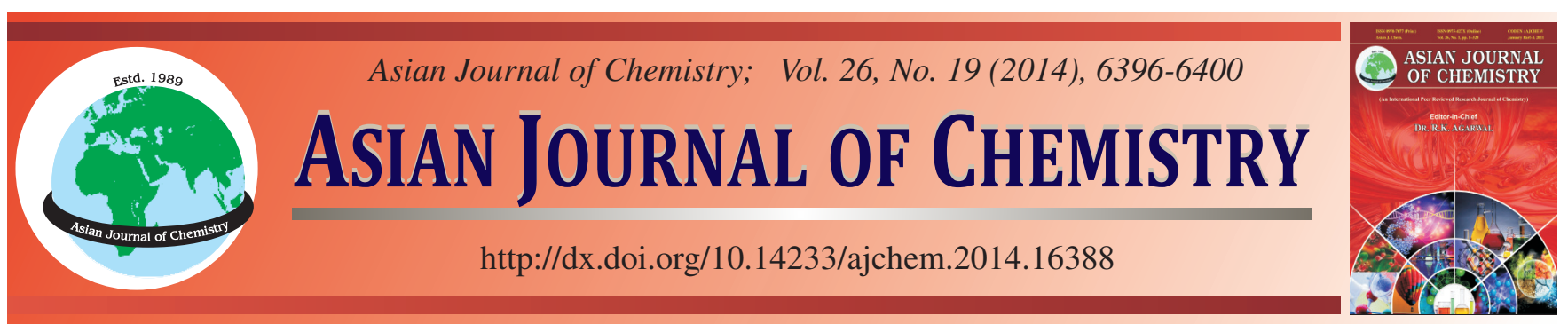

\title{
Effect of Activating Agents on the Development of Porous Activated Carbon Prepared from Prosopis juliflora Seeds
}

\author{
N. Gopal ${ }^{1, *}$, M. Asaithambi ${ }^{1}$, P. Sivakumar ${ }^{2}$ and V. Sivakumar ${ }^{3}$
}

${ }^{1}$ Department of Chemistry, Erode Arts College, Erode-638 008, India

${ }^{2}$ Department of Chemistry, AA Government Arts College, Namakkal-637 002, India

${ }^{3}$ Department of Chemistry, Sri Vasavi College, Erode-638 316, India

*Corresponding author: E-mail: chemgopal@yahoo.com

Published online: 16 September 2014;

AJC-15925

\begin{abstract}
Six varieties of activated carbon prepared from Prosopis juliflora seed using various chemical agents. The properties of the activated carbon's mostly depend on the production method and the type of the raw material. The maximum BET surface area obtained for an activated carbon prepared using $\mathrm{ZnCl}_{2}$ as an activating agent was found to be around $1137 \mathrm{~m}^{2} / \mathrm{g}$. All the physico chemical characteristics were analyzed and are comparable with the commercial as well as the activated carbon's reported in the past. In a view to apply for dyeing industry wastewater treatments, activated carbon prepared using $\mathrm{ZnCl}_{2}$ with polyaniline as an inert-matrix found to be most suitable. The prepared activated carbon were also analyzed for dye adsorption capabilities, acid and basic dyes show tremendous adsorption followed by reactive and direct dyes.
\end{abstract}

Keywords: Adsorption, Surface area, Activation, Polyaniline, Dyes.

\section{INTRODUCTION}

Human population is growing exponentially in countries like India. The growing population pollutes the water bodies in an alarming rate for their comfort and needs. Finding an economically low-cost and socially relevant treatment method is a hot area of research in recent years. Unfortunately, wastewater treatment method with fine results generally imply high energy/operation costs ${ }^{1}$. However, significant reduction of expenses and/or enhancement of treatment can be achieved by the combination of different methods in hybrid treatments ${ }^{2}$.

Inclusion of activated carbon (AC) in the liquid phase treatment is a successful technology for the effective wastewater treatment. Since, activated carbon is the most versatile adsorbent for the wastewater treatment because of its large surface area, polymodel porus structure, high adsorption capacity and variable surface characteristics ${ }^{3}$. It makes activated carbon's attractive to facilitate wastewater treatment is the possibility of tailoring their physical and/or chemical properties in order to optimize their performance ${ }^{1}$.

It has been reported that the surface area, pore volume, porosity and pore size distribution of activated carbon's have significant effects on the adsorption of organic pollutants s. $^{4,5}$. Numerous methodologies have been employed for the preparation of activated carbon's from various sources. Changing the physical conditions like steam activation, $\mathrm{CO}_{2}$ activation, activation in $\mathrm{N}_{2}$ atmosphere and also changing the activation temperature gives activated carbon's with different pore and surface characteristics. Another methodology for the preparation of activated carbon is the chemical methods, which employs the usage of various chemicals as an impregnating and activating agents. The role of these chemical agents are such that introduction of different functionalities and also enhancing the loss of volatile organic compounds and lignin from the carbon structure. The effective removal of these entities makes the activated carbon to become more porous with lot of micro and meso pores.

Though a number of activated carbon's are available in the market, but their high cost and selectivity towards certain class of pollutants limits their use in the industrial applications. This makes the exploration of an activated carbon from renewable plant based resources such as plam shell, coffee crop waste and tobacco residues $\operatorname{etc}^{6-11}$.

Prosopis has invaded millions of hectares of land in the arid and semi-arid continents of Asia, Africa, Australia and Americas. These species threatening crop production, depleting the water resources and displacing native flora and fauna ${ }^{12,13}$. Invasion of irrigation channels and arable land has affected the agricultural community and land owners and large, commercial farmers have seen their income threatened. These 
groups have put pressure on state governments, which have responded by asking forestry departments to stop further planting of Prosopis juliflora and begin eradication programmes, notably in Gujarat, Rajasthan, Haryana and Tamil Nadu. In India, chemical composition and nutritive value of Prosopis juliflora has been well reviewed and compiled. As a dry fodder, pods of Prosopis juliflora contain, $15 \%$ crude sugar, $12 \%$ crude protein, a moderate level of digestible crude protein with high level of energy; seeds contain $31-37 \%$ protein $^{14}$. However, the seeds are high in protein, are not easily digestible by animals, requiring some form of grinding and processing by humans.

Based on the above facts, Prosopis juliflora seeds are selected for the preparation of an activated carbon using various physical and chemical activation methods.

\section{EXPERIMENTAL}

Adsorbent preparation: The seeds of Prosopis juliflora were collected from in and around the rural regions of Erode District of Tamilnadu, India. The collected seeds were cut in to pieces of 2 to $4 \mathrm{~cm}$ size sun dried for one week. The dried material was used for the preparation of adsorbent as per the following procedures ${ }^{15}$.

Simple pyrolysis: In this method, the dried material was carbonized in a sealed ceramic oven at $550{ }^{\circ} \mathrm{C}$ for $20 \mathrm{~min}$. The material kept at $550{ }^{\circ} \mathrm{C}$ for $0.5 \mathrm{~h}$ before cooling it to room temperature. After carbonization, the material washed with plenty of distilled water, dried and ground well and then finally sieved into a particle size of 75 to $300 \mathrm{~m}$. The sieved carbon was placed in a sealed ceramic oven, heated at a rate of $5^{\circ} \mathrm{C} /$ min until the activation temperature of $800{ }^{\circ} \mathrm{C}$ and kept at this temperature for $0.5 \mathrm{~h}$ before cooling it to room in a desiccator. The cooled activated carbon (PJC1) was stored in tight lid container for further studies.

Acid process: The dried material was treated with excess of sulphuric acid or hydrochloric acid. Charring of the occurred immediately, accompanied by evolution of heat and fumes. When the reaction subsided, the mixture was left in an air oven maintained at $140-160{ }^{\circ} \mathrm{C}$ for a period of $24 \mathrm{~h}$. At the end of this period, the product was washed with large volume of water to remove free acid, dried at $110^{\circ}$ and finally activated at $800{ }^{\circ} \mathrm{C}$ (abbreviated as $\mathrm{PJC} 2$ for $\mathrm{HCl}$ and $\mathrm{PJC} 3$ for $\mathrm{H}_{2} \mathrm{SO}_{4}$ ).

Carbonization with $\mathrm{H}_{3} \mathrm{PO}_{4}$ : The material to be carbonized is impregnated with a boiling solution of $\mathrm{H}_{3} \mathrm{PO}_{4}$ for $2 \mathrm{~h}$ and soaked in the same solution for $24 \mathrm{~h}$ so that the solution get well adsorbed for a period of $24 \mathrm{~h}$. At the end of $24 \mathrm{~h}$, the excess solution decanted off and air-dried. Then the material was placed in muffle furnace carbonized at $400{ }^{\circ} \mathrm{C}$. The dried material was powdered and activated in a muffle furnace kept at $800{ }^{\circ} \mathrm{C}$ for a period of $10 \mathrm{~min}$. Then the material was washed with plenty of water to remove excess acid, dried and powdered (PJC4).

Carbonization with zinc chloride: The material to be carbonized is impregnated with a boiling solution of zinc chloride for $2 \mathrm{~h}$ and soaked in the same solution for $24 \mathrm{~h}$ so that the solution get well adsorbed for a period of $24 \mathrm{~h}$. At the end of $24 \mathrm{~h}$, the excess chloride solution decanted off and air-dried. Then the material was placed in muffle furnace carbonized at $400{ }^{\circ} \mathrm{C}$. The dried material was powdered and activated in a muffle furnace kept at $800{ }^{\circ} \mathrm{C}$ for a period of 10 min. After the activation, the carbon washed sufficiently with $4 \mathrm{~N} \mathrm{HCl}$ to remove the cations. Then the material was washed with plenty of water to remove excess acid, dried and powdered (PJC5).

Preparation of PJC5-polyaniline composite: The poly aniline was synthesized on PJC5 surface, which was previously soaked in monomer aniline solution $(0.2 \mathrm{M})$ for $12 \mathrm{~h}$ at room temperature followed by slow addition of chemical oxidants $0.5 \mathrm{M}$ Ammonium persulphate in $1.5 \mathrm{M} \mathrm{HCl}$ at room temperature for $4 \mathrm{~h}$ (PJC6).

Characterization of the carbons: $\mathrm{pH}$ and conductivity were analyzed using Elico make $\mathrm{pH}$ meter (model L1-120) and conductivity meter (model M-180), respectively. The physico chemical parameters were analyzed as per standard procedures $^{16,17}$.

Dye adsorption studies: In this part of study $0.1 \mathrm{~g}$ of adsorbent agitated with $100 \mathrm{~mL}$ of $50 \mathrm{ppm}$ dye solution for a period of $2 \mathrm{~h}$ at $200 \mathrm{rpm}$ in a temperature controlled orbital shaker.. The mixture was withdrawn at specified interval then centrifuged using electrical centrifuge (universal make) at 5000 rpm for $10 \mathrm{~min}$ and unadsorbed supernatant liquid was analyzed for the residual dye concentration using Elico make Bio-UV-visible spectrometer (BL-198). The amount of dye adsorbed at onto carbon was calculated by the following mass balance relationship:

$$
\mathrm{q}_{\mathrm{t}}=\frac{\left(\mathrm{C}_{0}-\mathrm{C}_{\mathrm{t}}\right) \times \mathrm{V}}{\mathrm{W}}
$$

where, $C_{o}$ and $C_{t}$ are the initial and equilibrium liquid phase dye concentrations $(\mathrm{mg} / \mathrm{L})$, respectively, $\mathrm{V}$ is the volume of dye the solution $(\mathrm{L})$ and $\mathrm{W}$ is the weight of adsorbent $(\mathrm{g})$.

\section{RESULTS AND DISCUSSION}

The physico-chemical properties of all the activated carbon's prepared using Prosopis juliflora were analyzed and presented in Table-1. Certain physical and chemical properties of activated carbon has very strong influence on the adsorption of solutes from their respective solution. By modifying the specific surface properties of activated carbon, it is possible to enhance its effectiveness for contaminant uptake from aqueous solutions ${ }^{18}$. Making changes in the surface of an activated carbon can result in vast changes in the dye and heavy metal adsorption characteristics.

All the six activated carbons have nearly neutral $\mathrm{pH}$. Only the carbon prepared using $\mathrm{H}_{2} \mathrm{SO}_{4}$ charring process has a $\mathrm{pH}$ of 6.72. The reason for this may be due to the residual acid in the interior pores of activated carbon. The activated carbon coated with polyaniline matrix has a higher $\mathrm{pH}$. Since polyaniline itself is a base material, which ultimately gives an activated carbon with higher $\mathrm{pH}$. To substantiate the results of $\mathrm{pH}$, conductivity measurements indicate that all the activated carbon have very low conductivity. The low conductivity shows that all the six activated carbon has very little amount of charged and exchangeable ions. Residual ionic compounds on the surface and pores are completely washed out, which results in poor conductivity. 
TABLE-1

PHYSICO-CHEMICAL PROPERTIES OF P. Juliflora SEED ACTIVATED CARBONS

\begin{tabular}{|c|c|c|c|c|c|c|c|}
\hline S. No. & Properties & PJC1 & PJC2 & PJC3 & PJC4 & PJC5 & PJC6 \\
\hline 1 & $\mathrm{pH}$ & 7.12 & 6.95 & 6.72 & 6.85 & 6.94 & 7.48 \\
\hline 2 & Conductivity $\left(\mathrm{mS} / \mathrm{cm}^{2}\right)$ & 0.082 & 0.118 & 0.222 & 0.248 & 0.156 & 0.273 \\
\hline 3 & Moisture content (\%) & 4.5 & 6.68 & 7.76 & 8.82 & 8.41 & 11.4 \\
\hline 4 & $\operatorname{Ash}(\%)$ & 10.1 & 11.2 & 14.8 & 19.7 & 15.6 & 16.4 \\
\hline 5 & Volatile matter $(\%)$ & 16.9 & 22.6 & 23.8 & 16.6 & 17.4 & 15.5 \\
\hline 6 & Matter soluble in water $(\%)$ & 0.55 & 0.36 & 0.44 & 0.46 & 0.51 & 0.44 \\
\hline 7 & Matter soluble in $0.25 \mathrm{M} \mathrm{HCl}(\%)$ & 1.54 & 0.99 & 0.86 & 0.99 & 1.18 & 1.27 \\
\hline 8 & Bulk density $(\mathrm{g} / \mathrm{mL})$ & 0.47 & 0.44 & 0.49 & 0.48 & 0.45 & 0.46 \\
\hline 9 & Specific gravity & 0.91 & 0.81 & 0.88 & 0.89 & 0.93 & 0.93 \\
\hline 10 & Porosity (\%) & 48.35 & 45.68 & 44.32 & 46.07 & 51.61 & 50.54 \\
\hline 11 & Surface area $\left(\mathrm{m}^{2} / \mathrm{g}\right)$ & 428 & 541 & 666 & 879 & 1137 & 1028 \\
\hline 12 & Methylene Blue value (mg/g) & 245 & 305 & 310 & 339 & 578 & 443 \\
\hline 13 & Iodine Number $(\mathrm{mg} / \mathrm{g})$ & 210 & 244 & 208 & 410 & 619 & 355 \\
\hline 14 & Phenol number $(\mathrm{mg} / \mathrm{g})$ & 10.55 & 9.91 & 10.7 & 13.3 & 11.8 & 11.15 \\
\hline 15 & Sodium $(\mathrm{mg} / \mathrm{g})$ & 0.54 & 0.88 & 0.37 & 3.9 & 0.22 & 0.26 \\
\hline 16 & Potassium (mg/g) & 0.91 & 0.92 & 0.7 & 1.05 & 0.49 & 2.1 \\
\hline 17 & Iron $(\mathrm{mg} / \mathrm{g})$ & 0.11 & 0.05 & 0.04 & 0.11 & 0.07 & 0.09 \\
\hline 18 & Fixed carbon $(\%)$ & 68.5 & 59.52 & 53.64 & 54.88 & 58.59 & 56.7 \\
\hline 19 & Yield $(\%)$ & 54.7 & 46.2 & 43.8 & 54.8 & 57.1 & 56.6 \\
\hline
\end{tabular}

$\mathrm{PJC} 1$ = Simple pyrolysis of Prosopis juliflora, $\mathrm{PJC} 2=$ Impregnation with $\mathrm{HCl}$ followed by activation, $\mathrm{PJC} 3=$ Impregnation with $\mathrm{H}_{2} \mathrm{SO}_{4}$ followed by activation, PJC4 = Impregnation with $\mathrm{H}_{3} \mathrm{PO}_{4}$ followed by activation, PJC5 = Impregnation with $\mathrm{ZnCl}_{2}$ followed by activation, PJC6 = Impregnation with $\mathrm{ZnCl}_{2}$ followed by activation and then doped with polyaniline

Activated carbon's (AC's) with well developed porosity and high surface area normally have the tendency to adsorb more quantity of moisture when exposed to atmosphere. Carbon prepared trough direct pyrolysis method has very little amount of moisture and all the other activated carbon's moisture content from 6.68 to $11.4 \%$. Particularly polymer doped carbon (PJC6) has high moisture adsorption capacity (Fig. 1). This could be due to the presence of more volume of mesopores.

Apart from the surface chemistry, textural properties of activated carbon's also play an important role. Most commercially available activated carbon's are predominantly mesoporous making them especially suitable for the adsorption of smaller pollutants ${ }^{1}$. The efficiency to adsorb larger molecules are expected to increase with increasing the fraction mesopores ${ }^{19}$. activated carbon's are modified by different acid salts as well as thermal treatments have been proved to show high adsorption capacity. Micropores provides good conditions for favourable adsorption, since the adsorbate molecules can interact with many surface simultaneously. Such type of carbon can be successfully employed as adsorbent and catalyst, the surface structure also enhances the adsorption of organic molecules and other solutes from gas or liquids.

The amount of ash and volatile matter is low in PJC1 (Fig. 1). Most of the weight loss occurred when the material heated to around $250^{\circ} \mathrm{C}$, as a result of physically held water being driven off ${ }^{20}$. When heating the material beyond $280^{\circ} \mathrm{C}$, a major amorphous cellulose breakdown caused the release of methanol, acetic acid, furfural and non-condensable gas consisting of $\mathrm{CO}$ and $\mathrm{CO}_{2}{ }^{21}$. Beyond $300{ }^{\circ} \mathrm{C}$ the hemi cellulose and cellulose started to depolymerize, producing volatile compounds ${ }^{21}$. At this temperature, rearrangement of carbon hetero bonds leads to the formation of carbon residue containing four carbon atoms and ultimately leads to the loss of hetero atoms. Above $500{ }^{\circ} \mathrm{C}$ probability of major changes is

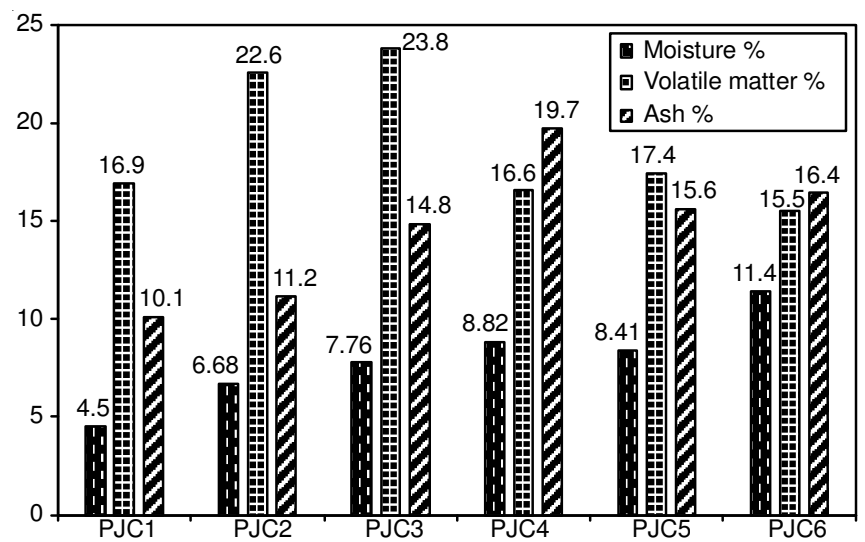

Fig. 1. Comparison of moisture, volatile matter and ash in PJC

less, the carbon skeleton settle with the removal of any residual hetero atoms.

High amount of volatile matter and ash was found in PJC2, PJC3 and PJC4. Activation with $\mathrm{ZnCl}_{2}$ and its polymer coated variant PJC5 and PJC6 has moderate amount of ash and volatile matter (Fig. 1). These values are comparable with the results reported by the past researchers ${ }^{22,23}$. Matter soluble in water and $\mathrm{HCl}$ found to be very low the activated carbon's prepared from biological materials (Fig. 2). This is more advantageous for an activated carbon which is employed for the treatment of dyeing industry effluent of varying $\mathrm{pH}$. Whatever be the variation in the $\mathrm{pH}$ of the effluent, which can not deteriorate the quality of activated carbon's. Bulk density of the six variant does not show any variation and also it is on the values generally observed in the activated carbon's.

All the six variants has excellent porosity of nearly $50 \%$. Though all the six activated carbon's has greater surface area, the PJC5 and PJC6 has exceptionally well developed porosity and very high surface area of 1137 and $1028 \mathrm{~m}^{2} / \mathrm{g}$ respectively (Fig. 3). As far as the precursor Prosopis juliflora seeds are 

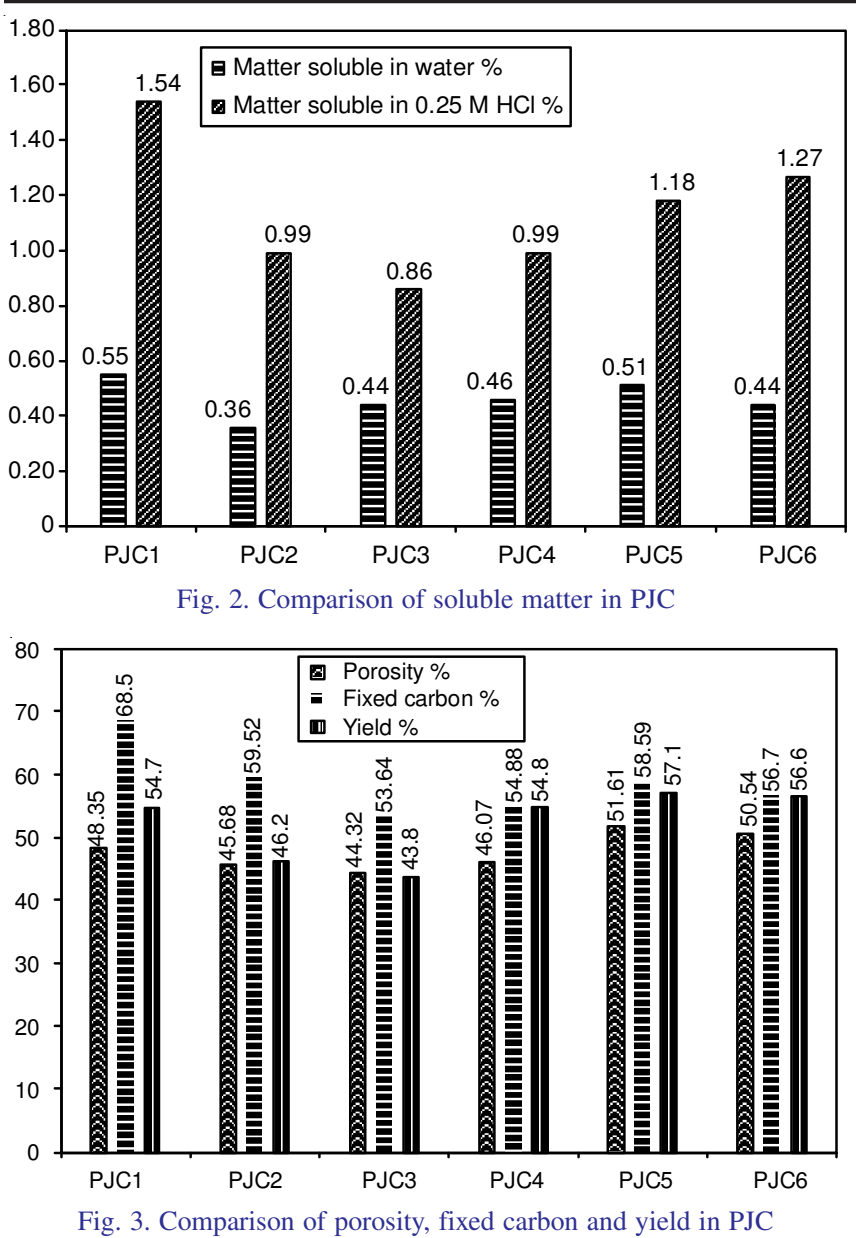

concerned $\mathrm{ZnCl}_{2}$ is the most suitable chemical agent for the effective removal of volatile organic compound's, lignin and other compounds. The chemical agent $\mathrm{ZnCl}_{2}$ paves the way for the removal of hetero atoms and enhances the formation of three dimensional carbon skeleton. The methylene blue number, iodine number and phenol adsorption capacity values substantiates the surface area observed PJC5 and PJC6 (Fig. 4). High value of phenol adsorption capacity indicates that the activated carbon's has tremendous potential towards the adsorption of large organic molecules. The iodine number is an indication of the aptitude of adsorbent towards the adsorption of small molecules and heavy metals ${ }^{23}$.

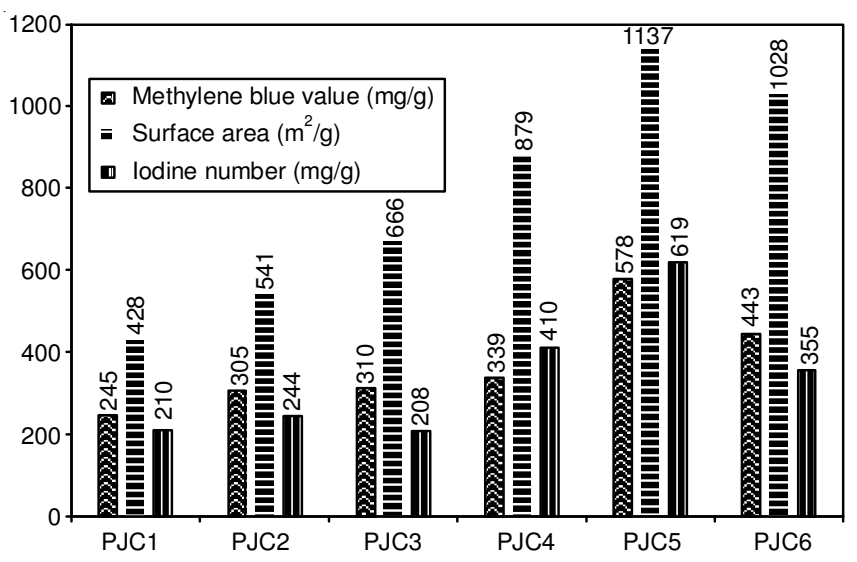

Fig. 4. Comparison of methylene blue value, surface area and iodine number in PJC
The residual $\mathrm{Na}, \mathrm{K}$ and $\mathrm{Fe}$ level are remarkably low and the activated carbon can be unfalteringly employed for wastewater treatment without any leaching of these metals. Low yield of 46.2 and $43.8 \%$ was observed for the carbon prepared using $\mathrm{HCl}$ and $\mathrm{H}_{2} \mathrm{SO}_{4}$. This could be due to high charring nature of $\mathrm{HCl}$ and $\mathrm{H}_{2} \mathrm{SO}_{4}$ makes the carbon slurry into colloidal form and little amount washed-out during the repeated washings. Except these two acid process, rest of the four processes gives activated carbon's with great yield of 54.7 to $57.1 \%$.

Further adsorption studies were performed with four classes of dyes namely acid, basic, direct and reactive dyes towards their sorption onto the six variants prepared activated carbon's. Out of the six carbons PJC5 and PJC6 has greater affinity towards rhodamine-B and acid violet. The amount of reactive yellow and direct green dye adsorption onto PJC5 and PJC6 is 82.6 and $80.4 \mathrm{mg} / \mathrm{g}$, respectively (Fig. 5). Generally reactive and direct dyes show poor affinity towards the activated surface. When compared to all six variants of activated carbon, PJC5 and PJC6 show good adsorption with reactive and direct dyes. Based on the superior qualities like more abrasion resistance and high mechanical stability, PJC6 is can lead the candidature for industrial applications over PJC5. High adsorption of various categories of dyes onto PJC5 and PJC6 suggests that pore diffusion plays an overriding role than surface adsorption by various functionalities through chemisorption.

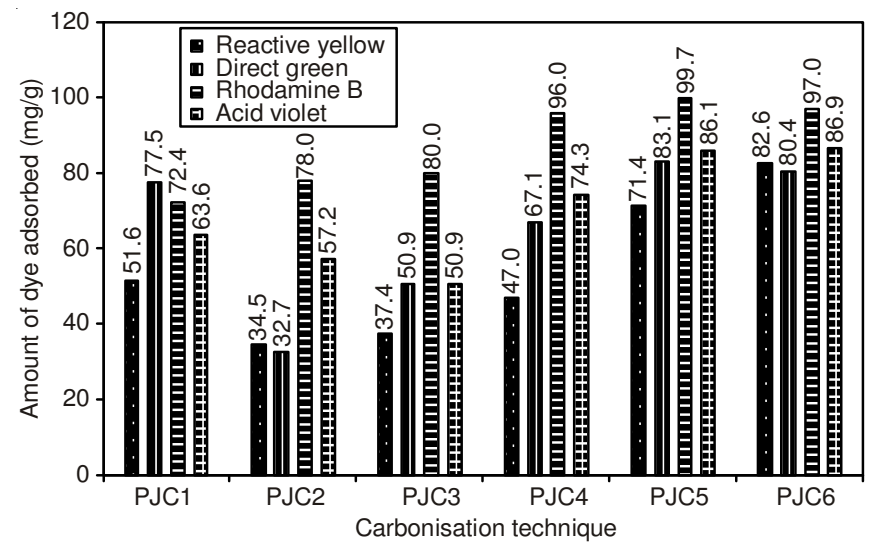

Fig. 5. Adsorption of various dyes on the PJC

\section{Conclusion}

An activated carbon with high surface area and good physico chemical characteristics was conveniently prepared from Prosopis juliflora seeds. Chemical activation using $\mathrm{ZnCl}_{2}$ gives an activated carbon having a surface area of $1137 \mathrm{~m}^{2} / \mathrm{g}$. The carbon PJC5 is coated with polyaniline matrix to improve the abrasion resistance and better mechanical strength. Polymer bound $\mathrm{ZnCl}_{2}$ activated carbon PJC6 was a superior adsorbent with a surface area of $1028 \mathrm{~m}^{2} / \mathrm{g}$. Dye adsorption studies also proves that PJC5 and PJC6 has greater potential towards the adsorption of four kinds of dyes namely acid, basic, reactive and direct dyes. PJC5 and PJC6 show greater affinity towards acid and basic dyes and little lesser affinity towards reactive and direct dyes. Prosopis juliflora seeds are low cost, renewable and easily available biomass with great potential to be a precursor for production activated carbon for wastewater treatment. 


\section{REFERENCES}

1. G. Mezohegyi, F.P. Vander Zee, J. Font, A. Fortuny and A. Fabregat, J. Environ. Manage., 102, 148 (2012).

2. F.I. Hai, K. Yamamoto and K. Fukushi, Crit. Rev. Environ. Sci. Technol., 37, 315 (2007)

3. H. Marsh and F. Rodríguez-Reinoso, Activated Carbon, Elsevier, Oxford Press, edn 1 (2006).

4. J.P. Marco-Lozar, A. Linares-Solano and D. Cazorla-Amoros, Carbon, 49, 3325 (2011).

5. P. Hnatukova, I. Kopecka and M. Pivokonsky, Water Res., 45, 3359 (2011).

6. X. Li, Q. Zhang, L. Tang, P. Lu, F. Sun and L. Li, J. Hazard. Mater., 163, 115 (2009)

7. M. Kilic, E. Apaydin-Varol and A.E. Putun, J. Hazard. Mater., 189, 397 (2011).

8. F. Bouhamed, Z. Elouear and J. Bouzid, J. Taiwan. Inst. Chem. Engg., 43, 741 (2012).

9. S. Altenor, B. Carene, E. Emmanuel, J. Lambert, J.J. Ehrhardt and S. Gaspard, J. Hazard. Mater., 165, 1029 (2009).

10. A. Fouladi Tajar, T. Kaghazchi and M. Soleimani, J. Hazard. Mater. 165, 1159 (2009).

11. M. Ajmal, R.A.K. Rao, J. Ahmad and R. Ahmad, J. Environ. Sci. Eng., 48, 221 (2006).
12. A. Witt, G.C.B. Bioenergy, 2, 321 (2010).

13. H. Zimmermann, J. Hofmann and A. Witt, Biocontrol News and Information, 27, 6 (2006).

14. R. Sawal, R. Ratan and S. Yadav, Asian-Australian J. Anim. Sci., 17, 719 (2004)

15. P.N. Palanisamy and P. Sivakumar, Rasayan J. Chem., 1, 901 (2008).

16. ISI, Activated Carbon, Powdered and Granular-Methods of Sampling and its Tests, (Bureau of Indian Standards, New Delhi), IS 877 (1989).

17. American Society for Testing Materials (ASTM), Standard Test Method for Determination of Iodine Number of Activated Carbon D4607-94, ASTM (1980).

18. C.Y. Yin, M.K. Aroua and W.M.A.W. Daud, Sep. Purif. Technol., 52, 403 (2007)

19. J.S. Macedo, N.B. da Costa Júnior, L.E. Almeida, E.F.S. Vieira, A.R. Cestari, I.F. Gimenez, N.L. Villarreal Carreño and L.S. Barreto, J. Colloid Interf. Sci., 298, 515 (2006).

20. A.C. Pastor, F. Rodríguez-Reinoso, H. Marsh and M.A. Martínez, Carbon, 37, 1275 (1999).

21. J. Zandersons, J. Gravitis, A. Kokorevics, A. Zhurinsh, O. Bikovens, A. Tardenaka and B. Spince, Biomass Bioenergy, 17, 209 (1999).

22. V. Sivakumar, M. Asaithambi and P. Sivakumar, Adv. Appl. Sci. Res., 3, 219 (2012).

23. S. Karthikeyan, P. Sivakumar and P.N. Palanisamy, E-J. Chem., 5, 409 (2008). 